\title{
"Em íntimo contato com a natureza": educação, saúde e trabalho na Escola Hospital José de Mendonça
}

\section{"In close contact with nature": education, health and labor at the School Hospital José de Mendonça}

\author{
Henrique Mendonça da Silva* \\ Heloísa Helena Pimenta Rocha**
}

\begin{abstract}
RESUMO
Este artigo busca examinar práticas instituídas na Escola Hospital José de Mendonça, criada no final dos anos 1930 em Araruama, interior do estado do Rio de Janeiro. Demarcada em seu espaço e em suas atividades cotidianas por intenções médicas e educativas, a escola hospital reuniu, primordialmente, crianças que frequentavam as escolas públicas da cidade do Rio de Janeiro, acometidas de males passíveis de cura ou tratamento. Nessa instituição, elas foram expostas à educação formal, ao trabalho e a práticas corporais calcadas nos pressupostos da medicina natural, dentre as quais os banhos de mar, a exposição ao sol e ao ar marítimo foram utilizados no tratamento dos casos doentios. Os objetivos visados pela escola hospital, concebida como uma espécie de contraponto à vida na cidade, com seus ritmos e seus males, articulavam-se em torno da crença no valor de uma natureza que restaura, alivia e tonifica. Os discursos de seu idealizador, o médico Oscar Clark, oferecem indícios do projeto mais amplo em que se inscrevia a iniciativa: um projeto modernizador, defendido por frações do pensamento social brasileiro, que tinha como pilares a cura de um povo considerado doente e a sua redenção por meio da alfabetização, do trabalho e das práticas de educação do corpo.
\end{abstract}

Palavras-chave: Higiene. Medicina natural. Escola hospital. Educação do corpo.

"Secretaria da Educação do Estado do Rio de Janeiro. Rio de Janeiro, Rio de Janeiro, Brasil. E-mail: enriquesh@msn.com - https://orcid.org/0000-0002-8968-0158

** Universidade Estadual de Campinas. Campinas, São Paulo, Brasil. E-mail: heloisah@ unicamp.br - https://orcid.org/0000-0001-7965-4100 


\begin{abstract}
This study aims to examine the practices of the School Hospital José de Mendonça, founded in the late 1930s in the city Araruama, in the countryside of Rio de Janeiro. With structures and activities marked by medical and educational reasons, the school first gathered children of public Rio de Janeiro schools, who suffered from treatable or curable diseases. This institution exposed the children to formal education, labor, and physical practices guided by natural medicine - for example, sea and sunbathing, exposure to sun, and sea air were used during treatment. The goals of the school-hospital, conceived as a counterpoint to busy and harmful city life, articulated with the belief in a nature that can restore, relieve, and invigorate. The discourses of the creator, Doctor Oscar Clark, offer clues about the bigger picture in which the initiative is inscribed: a modern project, defended by fractions of the Brazilian social thought, which had as cornerstones the cure of a people considered sick, whose redemption was literacy, labor and practices of body education.
\end{abstract}

Keywords: Hygiene. Natural medicine. School hospital. Body education.

\title{
FIGURA 1 - MENINOS DE ARARUAMA
}

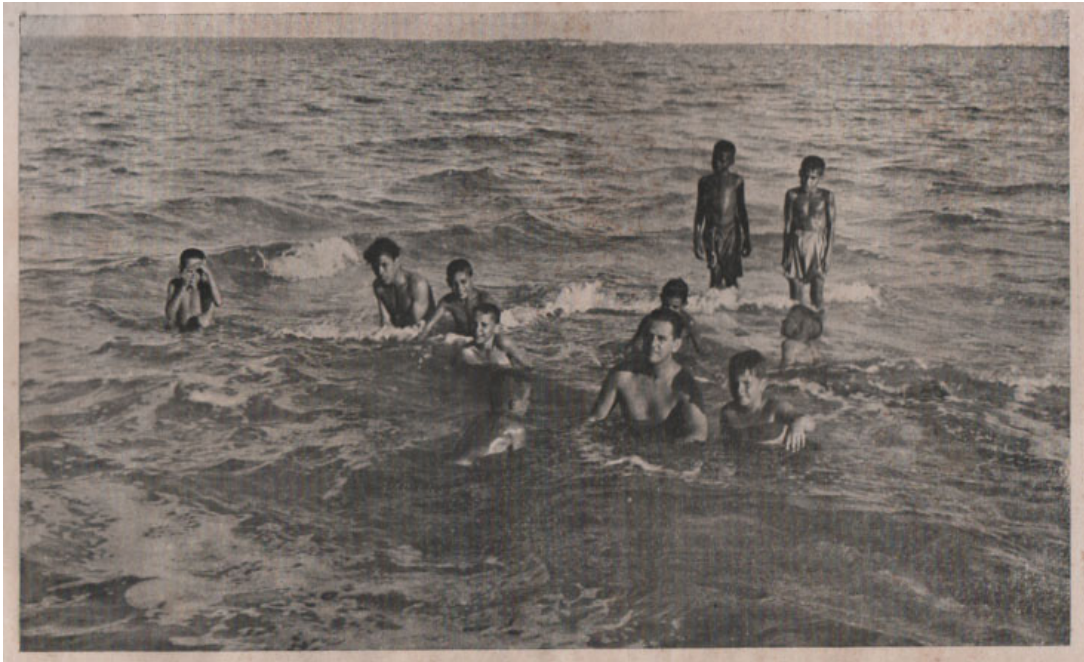

Nota: "Alunos da Escola Hospital José de Mendonça recitam Vicente de Carvalho - 'O mar é para mim como o céu para um crente'. A incomparável lagoa de Araruama. Ao fundo, a quilômetros de distância, avista-se a praia. Esses bancos de areia aumentam o valor médico social da lagoa de Araruama".

FONTE: (CLARK, 1946). 
Crianças se banham e se divertem na lagoa marítima do município de Araruama, no Rio de Janeiro, enquanto buscam a cura para os males que acometem os seus corpos. Esta é a mensagem sugerida pelo registro imagético e enfatizada por meio da legenda da fotografia dos alunos da Escola Hospital José de Mendonça, na qual o mar assume, numa alusão poética, o mesmo valor que o céu para os crentes. Acompanhados de um homem adulto, os meninos, com seus dorsos nus, trajam calções semelhantes. As águas em que se movem os seus corpos, pouco agitadas pelo vento, compõem a cena. A variedade de escolhas técnicas feitas pelo fotógrafo participa da codificação da mensagem contida na imagem fotográfica. $\mathrm{O}$ fotógrafo registra, de perto, a cena e os personagens, em filme preto e branco, com uma objetiva possivelmente entre 35 e $50 \mathrm{~mm}$ (lentes do tipo padrão).

Definido um enquadramento horizontal, a cena é composta por dois planos, com o fotógrafo de pé, buscando a centralidade do tema: "o banho de mar na lagoa". Enquanto isso, no segundo plano, o horizonte, próximo da borda superior da imagem e inclinado para a direita, é pouco definido e não muito atraente ao olhar. Esse plano provavelmente passaria despercebido, não fossem os sentidos afirmados pela legenda. Os signos verbais assumem um papel significativo na construção da mensagem presente no registro visual. Na conjunção entre a imagem e a legenda, procura-se afirmar o valor da paisagem (KOSSOY, 2000, 2001; LEITE, 2000) como parte do discurso da medicina social. O mar é tomado em um sentido de céu, de lugar povoado de bênçãos e plenitude, traduzido na expressão poética de Vicente de Carvalho: "O mar é para mim como o céu é para um crente". A frase parece central no esforço de configuração de uma representação quase religiosa dos benefícios do litoral como lugar de práticas civilizatórias, terapêuticas, econômicas e de divertimento - capaz de rearranjar os males causados pela vida no meio urbano e em cidades do interior. O discurso da legenda e sua articulação com a foto fazem retornar ao objetivo central: o banho de mar como prática corporal de um grupo de crianças que frequentavam uma escola hospital.

Durante quase sete anos, algumas dezenas de crianças usufruíram daquela "natureza marítima", trabalharam no campo em atividades agrícolas, receberam remédios, tiveram seu sangue investigado por exames hematológicos, seus pesos e medidas aferidos frequentemente, além de serem alfabetizadas. A grande maioria delas veio da cidade do Rio de Janeiro, passou pelos serviços de saúde escolar da cidade, que identificaram o seu estado de saúde e tentaram oferecer algum tratamento para os males identificados. Além das crianças da capital, outras, em menor número, eram oriundas do campo e sofriam das endemias que constrangiam homens, mulheres e crianças do interior, exigindo providências das autoridades públicas. 
Elas foram levadas até Araruama como parte de um experimento que prometia lidar com os quadros mórbidos que apresentavam, oferecendolhes educação formal e profissional, além de uma educação higiênica, que possibilitasse a elas assumir outra relação com a gestão da própria saúde. As formas de percepção dos problemas e as respostas que se procurou oferecer por meio da criação de instituições dessa natureza ganharam intensidade entre as décadas de 1910 e 1920, quando uma geração de cientistas e outros "artífices de um Brasil moderno" (HERSCHMANN; PEREIRA, 1994), deixando os centros urbanos, encontrou o que nomeou como um "país doente", povoado por uma população considerada "apática", "indolente" e "viciosa", mobilizando-se no sentido de identificar os objetos de intervenção, elaborar as estratégias e fornecer as justificativas (HOCHMAN, 2006).

Este artigo tem por objetivo examinar o lugar conferido às práticas que visavam educar o corpo infantil, fortalecê-lo, curá-lo e moralizá-lo, instituídas na Escola Hospital José de Mendonça, criada em Araruama, em 1939, como parte de um projeto capitaneado pelo médico Oscar Clark, com vistas a convencer o Estado da importância de cuidar das crianças doentes que frequentavam as escolas da cidade do Rio de Janeiro. Para tanto, toma como fontes fotografias e outros documentos produzidos no âmbito da instituição, debruçando-se, mais especificamente, sobre as práticas corporais ao ar livre, consideradas, juntamente com os cuidados relacionados à alimentação, as práticas de medição e pesagem dos corpos infantis e o ensino das noções de higiene, como meios de cura dos males que acometiam as crianças.

\section{"O efeito admirável da vida ao ar livre"}

Em janeiro de 1939 foi inaugurada a primeira escola hospital do País, à beira da lagoa de Araruama, na região da Pontinha, conhecida como Parque da Penha ou Sítio das Palmeiras. A propriedade estava há gerações com a família Mendonça e, naquele momento, havia passado às mãos de Oscar Clark e sua esposa. $\mathrm{Na}$ ocasião solene, autoridades estaduais, municipais, religiosas, além de vasta parentela dos Clark e dos Mendonça, reuniram-se no platô de uma das colinas da fazenda centenária e, em um ato simbólico, plantaram uma árvore.

A vontade de criar uma instituição dessa natureza foi manifesta, ainda em 1930, por Oscar Castelo Branco Clark, médico formado pela Faculdade de Medicina do Rio de Janeiro, em 1910, que se tornou mais tarde professor dessa mesma instituição. Clínico-chefe da $2^{\mathrm{a}}$ enfermaria da Santa Casa, primeiro 
médico-chefe dos serviços de inspeção médica escolar da cidade do Rio de Janeiro, era um dos defensores de uma ampla ação de medicina social. Seu anseio era que os alunos e a comunidade afetada pelas mais variadas doenças fossem beneficiados por ações que incluíam a descoberta dos problemas de saúde, a investigação social do percurso e das causas da doença pelos centros clínicos, o acompanhamento fisiológico (fichamento), bem como a cura pela ação das clínicas hospitalares.

Nove anos antes, em 1930, no discurso de inauguração de um centro clínico para crianças na cidade do Rio Janeiro, publicado na imprensa sob o título "Fins a que atendem as clínicas escolares", antes mesmo do fim da cerimônia, o médico lançou as bases de outro dispositivo de saúde escolar para as crianças, as clínicas escolares. Para ele, uma clínica escolar, como aquela que levava o seu nome, era apenas uma parte da estrutura. A cúpula, que encerraria os esforços, era outra.

A ideia de escolas hospitais, então apresentada, completaria o projeto de higiene escolar defendido por ele, sendo concebidas como a forma de atingir resultados em relação aos quadros doentios mais severos, que já haviam deixado sequelas físicas. Tais quadros exigiam longos períodos de tratamento, além do arsenal clínico da imunologia, terapia medicamentosa e pequenas intervenções cirúrgicas ou mesmo outros modos de cura, como o climático, a educação física e a atenção alimentar. Nesse sentido, o médico defendia uma proposta de hospitalização que possibilitasse não só levar a cabo o processo de cura, mas também promover a adesão do indivíduo aos preceitos da higiene.

Desde 1920, pesquisas que promoveram o fichamento médico dos escolares da cidade, feitas no âmbito da própria administração da instrução pública (LEÃO, 1926), ampliadas e sofisticadas com os conhecimentos e exames laboratoriais realizados na Clínica Escolar do Rio de Janeiro, passaram a dar conta da espantosa proporção de dois terços de alunos doentes (SILVA, 2017). Segundo avaliava o médico, "frequentavam as escolas inúmeras crianças débeis, em franco estado de miséria orgânica devido a dois grupos de causas, quase sempre combinadas: a) alimentação de má qualidade e em quantidade deficiente, b) presença de certas doenças [...]" (CLARK, 1930b, p. 64).

A escola hospital era pensada como um centro de tratamento de inúmeras morbidades, que se resolveriam sem uma "gota de remédio", apenas com a utilização das praias, da vida ao ar livre (terapia climática) e de uma boa alimentação (atenção alimentar):

Finalmente, como centro de tratamento de inúmeros casos mórbidos, em primeiro plano da tuberculose extra-pulmonar, os banhos de mar, aliados à helioterapia, à ótima alimentação e à vida ao ar livre, tem dado tão bons resultados $[\ldots]$ 
A salvação do Brasil sob o ponto de vista da saúde física depende, em grande parte, da utilização das praias e em parte alguma existem mais belas e mais próprias para a educação física das crianças do que em Araruama. Somadas às praias de Cabo Frio, podemos dispor aqui de mais de duzentos quilômetros de praias, que, sabiamente utilizadas, muito concorreriam para acabar com a tuberculose no Distrito Federal e no Estado do Rio de Janeiro (CLARK, 1939, p. 25).

Além da tuberculose, a experiência de realização de exames laboratoriais, iniciada em 1930, proporcionou a tomada de consciência das dimensões da sífilis entre as crianças cariocas:

4300 escolares foram examinados e rara foi a criança encontrada perfeitamente sadia. Nada pode haver de mais trágico do que a frequência de sífilis congênita e da tuberculose entre os alunos, o que explica o abarrotamento dos nossos hospitais, de condenados à morte precoce [...]. Os exames de laboratório (de Wassermann e Roentgen) mostram, com efeito, que em cada grupo de quatro alunos, há um com sífilis congênita, outro com tuberculose ganglionar ou pulmonar (PEREIRA, 1932, p. 150).

Considerando os limites do conhecimento médico disponível no período em relação a essas enfermidades, as escolas hospitais poderiam ser uma forma de garantir a execução dos tratamentos. $\mathrm{O}$ enfrentamento da tuberculose abarcava, à época, pelo menos duas dimensões: a médica, com suas formas de diagnóstico e terapêutica; e a social, que levava em conta os fatores relacionados ao meio e às condições econômicas e culturais dos sujeitos. Não era um problema a ser resolvido tão somente pelos médicos, até porque não existia uma terapêutica específica ou um fármaco eficiente, apenas em 1944 chegou-se à descoberta da estreptocmicina

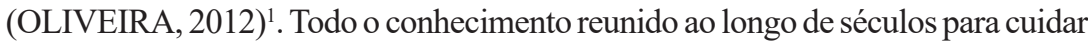
e controlar essa patologia abarcava uma variedade enorme de procedimentos, como a helioterapia, a atenção alimentar e os cuidados em sanatórios.

Se nos detemos na legenda da fotografia com a qual iniciamos este artigo, buscando compreender o que se pretendia com as práticas encenadas, uma expressão pode ser destacada: o "valor médico social da lagoa de Araruama".

1 Sua comercialização em larga escala somente ocorreu no final de 1948, passando a ser um fármaco reconhecido como eficiente. 
Sobre isso, Clark lembrava que: "há 25 anos que estudo o problema da tuberculose, na qualidade de clínico e educador, e posso afirmar que enquanto não se descobrir um medicamento contra o mal, é uma ilusão considerar que a profilaxia da doença é problema essencialmente médico" (CLARK, 1943, p. 24). E efetivamente não era. Como já se sabia, desde o século XIX, era um problema que dependia de escolhas políticas e econômicas, na medida em que se relacionava às condições de vida, moradia, nutrição e trabalho da população. Para Chalhoub (1996), as escolhas de enfrentamento de certas doenças e a consequente demora em relação a outras devem ser percebidas criticamente, buscando-se os seus sentidos; o adiamento do combate a doenças como a tuberculose colocava em xeque a neutralidade e a "cientificidade" das decisões médicas. Ao médico cabia, entretanto, ser seu fiador, dando resposta à amplitude do problema por meio da seleção dos aspectos a serem observados e da indicação da terapêutica a ser adotada.

Herschmann e Pereira (1994) examinam o percurso dessa visão intervencionista e o papel das reivindicações desses intelectuais na constituição de diretrizes para a sociedade brasileira. A postura missionária, em defesa de uma causa, aparece de forma muito bem acabada na introdução da obra "O Século da Criança", em que se afirma que o médico é o "advogado natural da humanidade" (CLARK, 1940, p. 5). A escola hospital era, assim, uma resposta médica e social, que elegia nas práticas de cura pela natureza sua forma de intervir.

A regeneração e fortalecimento do corpo pela natureza era um dos repertórios terapêuticos mais aceitos para a cura da tuberculose. De acordo com Baubérot (2004) e Villaret (2005), o emprego da luz solar e do ar de altitude para a cura de doenças compôs, ainda na segunda metade do século XIX, uma corrente médica denominada medicina natural. Desenvolvida inicialmente em territórios germânicos, rapidamente encontrou eco em diferentes países, resultando na formulação de grande número de propostas, como a hidroterapia, a helioterapia e a climatoterapia. Vivia-se, no início do século XX, uma ressignificação da natureza, traduzida na crença de que ela tudo poderia oferecer, sendo capaz de curar e educar (SOARES, 2016). No campo da proteção à infância, destacam-se, no período, instituições como sanatórios, solários, preventórios, colônias de férias infantis e escolas ao ar livre, assim como propostas de adequação da arquitetura dos edifícios escolares, a fim de que os alunos pudessem ter contato direto e constante com a luz do sol e respirar ar puro (DALBEN, 2014; SILVA, 2017).

Assim, os meninos registrados pelas lentes de um fotógrafo não estavam apenas tomando banho em uma lagoa. Eles estavam inseridos em práticas calcadas em conhecimentos do campo médico, os quais postulavam que a exposição do corpo a determinados elementos da natureza - como a água, o sol e o ar livre, em um ambiente adequado - propiciaria a cura dos males de que sofriam, restituindo-lhes a saúde. 
Escolas hospitais no campo é um assunto muito em voga atualmente; condições ideais para uma perfeita educação física das crianças ao ar livre em intimo contato com a natureza. As realizações científicas desde a primeira grande guerra mostram de maneira convincente o valor imenso dos banhos de ar, do campo e das praias, de sol e de mar, para o revigoramento do corpo e a profilaxia e cura de graves estados mórbidos - a tuberculose em primeiro plano. A experiência de todos os médicos que lidam com as manifestações extra pulmonares é unânime na afirmativa de que os casos mais graves se curam como por encanto ao fim de alguns meses de permanência no campo, ou na praia, sob a influência da hélio e da talassoterapia. Todas as investigações psicológicas provam o efeito admirável desta vida ao ar livre sobre a alma das crianças: mostram muito maior decisão, energia, atividade e alegria (CLARK, 1946, p. 16-17).

A fotografia dos meninos da escola hospital indicia um significativo investimento por parte de Oscar Clark, desde os anos iniciais da década de 1930, no sentido de afirmar as qualidades e funções terapêuticas do clima da região. Até certo ponto, na ocasião, a escolha de Araruama pode ser lida como uma mudança de direção. As praias e regiões de clima ameno marítimo (próximas ao sertão) eram frequentemente apontadas pelos médicos do século XIX como as mais apropriadas para a cura dos tísicos; porém, a partir da década de 1920, motivados pelas experiências sanatoriais nas serras paulistas, essas regiões perderam importância (BERTOLLI FILHO, 2001, p. 138). Por isso, cantar em prosa e verso as belezas naturais e as funções terapêuticas de Araruama fazia parte de uma estratégia de convencimento não só daqueles que procuravam formas de tratar seus males e preservar a vida, mas também dos governantes, incentivados a investir na infraestrutura da região, com base nas justificativas médicas.

As reflexões de Corbin $(1989$, p. 65) acerca das representações das praias no Ocidente mostram-se instigantes para a compreensão das iniciativas do médico. Na obra "O território do vazio", o autor examina o percurso das imagens de praias, situando o século XIX como o momento em que, com o romantismo científico, deu-se o despertar do desejo coletivo das praias. Em relação aos usos do litoral no Brasil como lugar adequado para práticas corporais voltadas para a cultura física, o estudo de Montenegro (2020) indica as aproximações com o que foi experienciado pela comunidade inglesa nesse mesmo século.

Duas ideias se mostravam possíveis no projeto de Clark: a primeira era fazer um balneário voltado para terapias climáticas, cujo fundamento era a talassoterapia - que consistia no emprego dos banhos de mar, investidos de propriedades terapêuticas, como parte de um longo processo de descoberta das virtudes do mar (CORBIN, 1989); a outra ideia era fazer da região uma "higienópolis infantil", 
um grande abrigo de "menores em situação de risco", ligado ao balneário turístico (SILVA, 2017). Em 1941, o médico, então chefe do serviço de escolas hospitais do Departamento de Instrução do Rio de Janeiro, saudava o projeto do diretor de Instrução do Distrito Federal, professor Pio Borges, que visava criar "aldeias educacionais". Em um artigo no Correio da Manhã, explicava que as "aldeias" pretendidas pelo diretor constituíam-se em uma série de edificações construídas no campo, no entorno das escolas hospitais, com o objetivo de promover momentos de diversão, cultura e aprendizagem de técnicas de trabalho, uma vez que, segundo ele: "As aldeias educacionais compõem o ambiente propício à benéfica influência exercida pelas escolas hospitais" (CLARK, 1943, p. 4).

O projeto contemplava a possibilidade de exposição dos corpos infantis a elementos da natureza, como já se apontou, além da diminuição dos ritmos da vida (repouso), pensadas como formas de educação do corpo (SOARES, 2016). A isso se associava o intento de criação de um centro de diversão ao ar livre (conhecido no jargão médico terapêutico do período como "banhos de ar") para os frequentadores adultos. Essas duas intenções estavam presentes no termo que aparecia com frequência nos pronunciamentos e textos do médico, que propunham fazer do lugar um "centro social", concebido como uma experiência moderna (CLARK, 1939, 1943). Termo esse que remete à presença de uma cultura física mediada pela higiene, com o incentivo das práticas corporais (exercícios sistemáticos do corpo) para obtenção da cura, bem como uma performance social de corpos saudáveis (KIRK, 1999; MORAES E SILVA; QUITZAU; SOARES, 2018). Um trecho do seu discurso na inauguração da escola hospital pode ser muito útil para exemplificar tal conjunto de intenções sobre Araruama e seu entorno - a baixada litorânea fluminense.

Que seja, essa terra de promissão, com suas planícies maravilhosas, solo, ubérrimo, clima ameno e sobretudo com sua lagoa de uma beleza inebriante, que mais lembra um lindo pastel sinônimo de amor, isto é, a cidade da criança. Que seja o Brasil o berço da nova civilização baseada na ciência! Ninguém até hoje compreendeu a importância social da lagoa de Araruama como centro de turismo, nada conheço de melhor e talvez, nada haja no mundo que se the compare como centro de talassoterapia social. Nada como o mar para modificar a constituição franzina das crianças das grandes cidades, para restaurar as energias esgotadas dos homens do trabalho ao se aproximarem dos fatídicos 40 anos, nada existe comparável ao valor das praias e talvez, por isso escreveu Hardy com muita felicidade que a água do mar é "la prémiere des eaux minérales", quis ele dizer que entre a praia e a estação hidromineral ninguém deve vacilar na escolha de uma estação de repouso (CLARK, 1939, p. 24, grifos nossos). 
Ninguém, até hoje, compreendeu a importância social da lagoa de Araruama. As suas imensas riquezas naturais ficam na penumbra, se atentarmos para sua significação social.

Como centro de turismo, nada conheço de melhor e talvez, nada haja no mundo que lhe compare como centro de talassoterapia social. Distante apenas noventa quilômetros de Niterói, à qual está ligada por boa estrada de rodagem e contando 192 quilômetros de praias admiráveis, constitui a lagoa de Araruama uma imensa banheira infantil de 220 quilômetros quadrados de superfície (CLARK, 1943, p. 142).

As calmas águas da lagoa de Araruama, com ondas que açoitavam os corpos com a segurança de uma piscina infantil (CLARK, 1943, p. 43); as brisas marítimas com seu frescor a exercitar os pulmões, em suas contrações e relaxamentos; e as areias a estimular os músculos, eram parte integrante da cura e da educação pela natureza (SOARES, 2016). O tempo junto à natureza que a organização da escola hospital cobrava era um tipo de intervenção médica individual, para salvaguardar o organismo da doença e estimular sensibilidades, o que redundaria em uma educação da população por meio dos benefícios da natureza e seus elementos. Boa parte do que se planejava para o espaço passava por esta mediação, desde a disposição dos prédios e as práticas de trabalho, até a demarcação do tempo; aspectos cuja definição levava em conta os benefícios que se queria extrair da natureza como fonte terapêutica.

De um momento para o outro, as praias adquiriram imenso valor médico social; a talassoterapia passou a ser um dos recursos mais apreciados para o revigoramento do corpo. As areias das praias passaram em pleno século XX a ser as areias da vida, de que profeticamente nos falou Charles Dickens e as águas do mar são consideradas no mundo moderno como as verdadeiras águas milagrosas. Da superfície das águas do mar refletem, em abundância prodigiosa, raios ultra-violeta, à brisa marítima, ao notável efeito psicológico exercido pelas praias, sobre a alma das crianças, à ação da água salgada sobre o organismo e à intensidade dos raios solares constituem um dos recursos mais úteis e agradáveis da terapêutica geral (CLARK, 1943, p. 73). 


\section{Outras relações com a natureza: o ideal do trabalho}

Engana-se quem acha que só de banhos de mar, sombra (repouso), alimentação saudável e água fresca se compunham os receituários de práticas terapêuticas para aqueles meninos. Outro tipo de prática corporal ao ar livre também deveria ser adotado, para o bem dos projetos de modernidade brasileiros e da manutenção da estrutura material da instituição. Assim, ao mesmo tempo em que se pregava a necessidade de expor aqueles alunos às propriedades terapêuticas do sol, da brisa marítima, articulava-se o seu engajamento nas atividades agrícolas, com vistas a desenvolver o gosto pelo trabalho, um valor social tão caro a intelectuais como Clark quanto a cura da sífilis e da tuberculose.

FIGURA 2 - CRIANÇAS TRABALHANDO NA HORTA DA ESCOLA HOSPITAL JOSÉ DE MENDONÇA

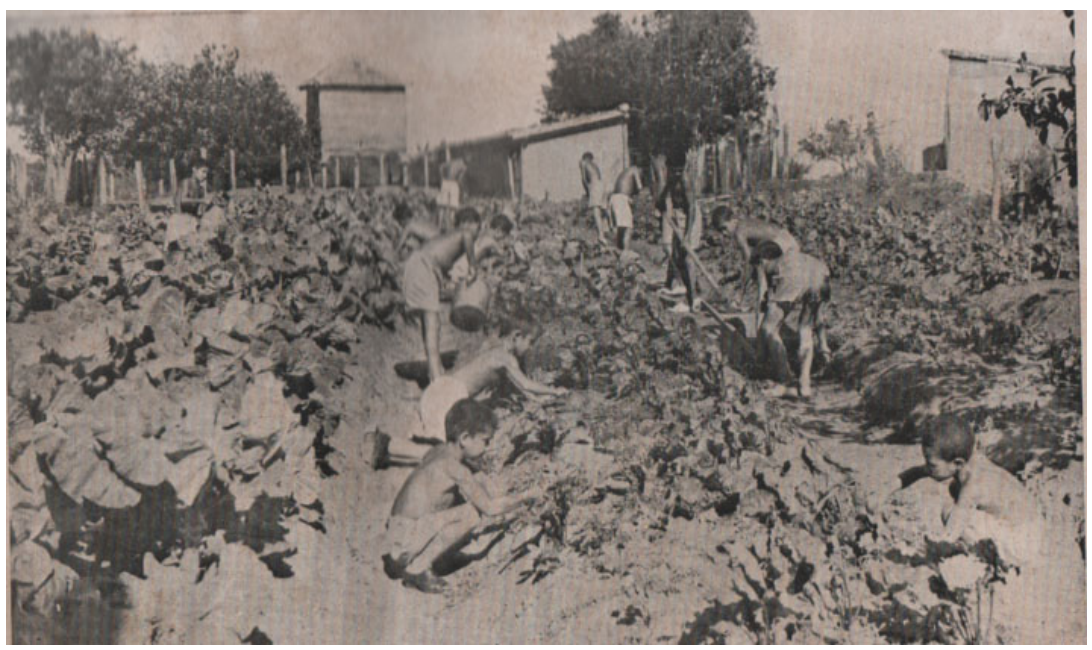

Nota: "Não há ocupação superior a agricultura; nada mais produtivo nem de maior doçura ou que seja mais digno do homem livre" - Cícero. Local: Araruama, Fazenda da Penha.

FONTE: (CLARK, 1946).

Neste outro registro fotográfico das atividades da escola hospital de Araruama, crianças ao ar livre, expostas ao sol, trabalham na horta da instituição. A legenda apela a outra dimensão das práticas ali instituídas: a dimensão "sanitária" e social que o trabalho deveria ter para essas crianças. Sozinhos, portando instrumentos de trabalho apropriados ao seu tamanho, os meninos, com os dorsos 
nus, trajam calções semelhantes. $\mathrm{O}$ fotógrafo retrata de perto os participantes da cena. A fotografia é feita em um enquadramento horizontal, sendo a cena composta em dois planos. $\mathrm{O}$ ângulo mais próximo ao chão e a manutenção do quadro reto permitem focar os meninos em pleno trabalho, na linha central da imagem. A centralidade do tema incide sobre o "trabalho de crianças" (primeiro plano), enquanto o segundo plano é repleto de informações sobre os objetos e as atividades regulares que faziam parte do cotidiano da instituição.

Exibem-se prédios sem padronização, cada um com seus recortes e descontinuidades, que sugerem construções e adaptações mais recentes, feitas em função da criação da escola hospital e das demandas de cuidado das crianças. Os objetos de uso coletivo, como enxadas e baldes, e de uso pessoal, como os calções e sapatos dos meninos, ligam-se nessa cena de trabalho agrícola. É preciso atentar também para a figuração e a vivência (ESSUS, 1990, 1993). A cena foi certamente construída para a documentação feita pelo fotógrafo, elegendo como foco as crianças na relação com trabalho coletivo (figuração), horta e cerca.

O registro fotográfico e a legenda articulam-se em torno da construção do ideal de superioridade das atividades agrícolas e da promessa de liberdade que elas supostamente representavam: "Não há ocupação superior a agricultura; nada mais produtivo nem de maior doçura ou que seja mais digno do homem livre" (CLARK, 1946, p. 49). As expressões empregadas na legenda apontam para os ideais civilizatórios propalados pela geração de intelectuais a que pertencia Clark. Trabalho e liberdade compõem um par, no âmbito do projeto desenhado por esses homens. Nesse sentido, o médico manejou argumentos e temas caros ao movimento escolanovista, como alfabetização e trabalho (SILVA, 2017). A estrutura da fotografia, em sua codificação e decodificação, representa um esforço de justificativa da importância das práticas laborais em um cotidiano recortado por atividades apresentadas como salutares e regeneradoras.

Tentava-se, nesse sentido, enfrentar alguns problemas: (1) valorizava-se o trabalho como um exercício utilitário, por meio de uma operação que o inseria no rol das práticas corporais na natureza, construídas em oposição à fraqueza física e moral e ao ócio dos "doentes", ao mesmo tempo em que (2) se instituíam práticas de tratamento/manutenção da saúde. $O$ fato de as crianças internadas realizarem trabalhos agrícolas como parte do tratamento médico e da sua educação, ajustava-se muito providencialmente à preocupação com (3) o peso econômico da instituição para o Estado. Todas essas questões eram bem-vistas e desejadas. Estava em jogo a educação para o trabalho: o "trabalho físico" (agrícola), investido de inequívoco valor moralizante, era considerado como o mais apropriado para as classes populares a que certamente pertenciam essas crianças. As dimensões sociológicas do que se pretendia eram 
amplas: oferecia-se a alfabetização e a educação para o trabalho, (4) evitando-se o deslocamento do homem do campo para a cidade, como também combatendo o funesto vício da bebida, a desordem social, bem como as endemias rurais.

A educação na escola hospital concorre, ainda, para combater o vício do alcoolismo, um dos flagelos do meio sertanejo. A escola é ótimo meio de saneamento rural. Ela serve, para fixar as populações no campo, para povoar o campo, e se transforma, por isso mesmo, em poderoso elemento auxiliar da realização do lema - RUMO AO OESTE (CLARK, 1943, p. 123).

As escolas hospitais cuidam da educação integral das crianças (higiene, ótima alimentação e tratamento para recuperar e manter a saúde, instrução, educação física, moral, cívica e religiosa e criação do hábito do trabalho). Preparam as crianças para a vida. Atendem, deste modo, a três fins: terapêutico, educativo e vocacional (CLARK, 1943, p. 132).

Clark comungava da ideia de muitos intelectuais do seu tempo, que consideravam que, por meio da incorporação de amplas camadas da população ao projeto de educação (de um determinado tipo), seria possível inserir o país nos rumos do progresso. Muitos deles eram médicos, como Miguel Couto, e acreditavam que "o progresso de um país está na razão direta da cultura de um povo" (COUTO, 1927, p. 6); outros, advogados, engenheiros e empresários, como Carneiro Leão, Sampaio Doria, Fernando Magalhães. Vários deles pertenciam às mais diversas entidades criadas no período, como a Liga de Defesa Nacional, a Liga Fluminense contra o Analfabetismo e a Associação Brasileira de Educação. O projeto de afastamento das crianças pobres dos seus lares defendido por Clark não poderia, pois, descurar da escolarização dessas crianças (CLARK, 1943, p. 43), sob pena de se perder esse decisivo instrumento de aceleração histórica, capaz de influir em dimensões consideradas importantes pelo pensamento social e político, como o civismo, o trabalho e a higiene.

Essa crença, que ganha ênfase sobretudo a partir dos anos 1920, foi examinada em importantes estudos sobre a história da educação no Brasil. Nagle (1976) e Carvalho (1998), a partir de perspectivas distintas, trazem contribuições significativas para a análise das discussões sobre a alfabetização dos brasileiros, promovidas por associações civis e religiosas, partidos políticos e intelectuais, no período. $\mathrm{O}$ analfabetismo foi configurado, conforme apontam os autores, como uma categoria explicativa, que procurava demonstrar o descompasso do povo em relação às instituições públicas, a um projeto de nação e a formas de trabalho ordenado mais modernas. 
Identificada como um freio ao progresso do País, como problema nacional por excelência, desde a década de 1910, a causa do analfabetismo mobilizou intelectuais reunidos em torno de associações (CARVALHO, 1998; NOFUENTES, 2008; PAULILO, 2011; ROCHA, 1995), que tomaram como eixo das suas iniciativas a educação do povo, buscando definir o tipo de escola e os conteúdos da escolarização das camadas da população historicamente excluídas das benesses da civilização (CARVALHO, 1989). Clark se manteve atento a essa discussão e manejou com habilidade os principais argumentos que envolviam a questão, sendo contrário ao que chamava de "fetichismo dos diplomas superiores" e considerando mais adequada uma educação que tivesse um claro viés técnico agrícola (CLARK, 1943, p. 65), distribuída por classe, como deixa claro ao criticar a instrução das camadas populares: "Aos que terminam o curso, as escolas municipais limitam-se a dar instrução puramente livresca; são tratados como se fossem filhos de ricos; não são educados na religião do trabalho. Esse método pedagógico está condenado há vários séculos" (CLARK, 1943, p. 141).

O trabalho, nos moldes previstos pelo programa da escola hospital, representava para as crianças pobres um tipo de educação mais útil à manutenção do status quo. A posição do médico expressava uma predileção pelo trabalho no campo e pautava-se na atribuição de um valor negativo à cidade e aos hábitos de suas populações. A crença em que o futuro do Brasil estava no campo era defendida por muitos dos que se alinhavam a propostas como a que redundou na criação da escola hospital. Para eles, o modelo agrário configurava-se no mais lógico para um país com as proporções do Brasil. Referindo-se a essa questão, Nagle (1976, p. 15) aponta a presença de uma "ideologia do ruralismo" na sociedade brasileira, que se traduzia na "ideia de que a felicidade do homem brasileiro esteve e está ligada ao meio rural, fonte de energia, de saúde, de pureza de costumes".

Tal concepção movimentava interesses econômicos e pesava sobre os projetos de desenvolvimento industrial. Assim, o médico não estava sozinho. $\mathrm{Na}$ Primeira República, intelectuais de formações distintas, com fortes vínculos políticos e econômicos, reuniram-se em ligas e associações militantes pela causa da educação, onde discutiram projetos de modernização do país. A "vocação rural" versus o futuro anunciado pela presença das fábricas no meio urbano tiveram rebatimento em modelos escolares marcados pelo viés utilitarista (CARVALHO, 1998; MONARCHA, 1989). Outros representantes do nosso pensamento social, como Oliveira Vianna e Alberto Torres, eram expoentes da via rural como forma de assegurar o progresso do País. Entre os educadores, figuras como Sud Mennucci e Antônio Carneiro Leão também se destacavam como defensores dessa vertente.

Mas a escola hospital, não esqueçamos, era fundamentalmente um centro de tratamento de inúmeras morbidades, que tinha como eixo as práticas corporais 
na natureza. Boa parte das práticas de cura e de educação instituídas tinha como objetivo o mal dos pulmões e seu tratamento. A definição das formas de arejamento dos prédios e da configuração dos espaços levava em conta a maior exposição possível a uma natureza que cura. Uma declaração dos idos de 1940 é precisa nesse sentido: "julgo indispensável mudar a mentalidade dos nossos educadores. É preciso convencê-los de que construir prédios escolares é quase jogar dinheiro fora. Precisamos abrir escolas debaixo das árvores, construindo meros abrigos para os dias de chuva" (CLARK, 1940, p. 160).

A organização do trabalho e a demarcação do tempo também expressavam os benefícios que se queria extrair da natureza como fonte terapêutica. A talassoterapia, com o uso terapêutico dos banhos de mar para produzir efeitos fortificantes, adstringentes e resolutivos, seria a expressão do uso simbiótico de uma natureza benfazeja, que cura e educa (VALENZUELA; BACAICOA, 1994). O projeto da escola hospital baseava-se, desse modo, na junção conceitual e prática de uma instituição educativa e de cura, constituindo-se, por essa via, em hospital, preventório, escola para débeis e escola ao ar livre. O local se caracterizava como uma "instituição total", conceito formulado por Goffman (1974) para definir os estabelecimentos que concentravam grande número de indivíduos em semelhante situação, apartados da sociedade por um tempo considerável, levando uma vida reclusa e fortemente administrada.

O tempo dedicado à natureza no âmbito da escola hospital consistia em um tipo de intervenção médica individual. Por trás do discurso de uma natureza benevolente com forças tonificantes e curadoras, é possível pensar em intenções de reclusão social e de controle do corpo infantil, com o afastamento de um meio considerado maléfico à saúde, pelo maior tempo possível - a vida urbana, com suas contaminações e contradições, e a casa anti-higiênica. Em texto, que sob muitos aspectos pode ser considerado definitivo em relação ao projeto intelectual das escolas hospitais, intitulado A política dos campos de saúde: escolas hospitais silvestres (CLARK, 1946), o regramento do tempo e a definição dos ritmos das práticas de saúde adotadas são muito bem apontados:

O trabalho porém tem apenas finalidade educativa e atrelado a capacidade física e a idade de cada um. Horário nessas escolas hospitais, deve ser assim distribuído:

Três horas de trabalho no campo;

Três horas para refeições;

Três horas para o estudo;

Três horas para diversões e repouso durante o dia;

As noites devem ser livres (CLARK, 1946, p. 46). 
As atividades, os tempos, os espaços, os movimentos e os controles respondiam a uma utilidade, aproximando-se do que Foucault (2007) denominou disciplinas, para se referir à constituição de um homem máquina, manipulável e consertável por uma série de procedimentos técnicos, políticos e moralizantes. A instituição lançava mão, assim, de um receituário composto por um conjunto de atividades ao ar livre, escolhidas com base na crença nos benefícios advindos de tais práticas para os corpos infantis, os quais se traduziam em curas naturais para os males de que sofriam. Disciplinava-se o corpo para extrair o máximo proveito da natureza, ao mesmo tempo que se procurava controlá-lo, em busca de um ideal ascético, do domínio de cada um sobre si, com base nos preceitos da doutrina higienista, que preconizava a disciplina em prol de um ideal maior: a restituição da saúde e a incorporação de costumes.

Uma rápida volta no tempo pode ser útil para não perdermos de vista uma dimensão importante. O projeto médico das escolas hospitais era uma ação de Estado, manejada por médicos a ele ligados. Seu percurso começou nove anos antes, quando o fichamento anatomopatológico e os exames laboratoriais começaram a ser feitos extensivamente e permitiram identificar a proporção de dois terços de crianças doentes nas escolas (CLARK, 1930a, p. 361-367). Essa proporção, recorrentemente observada (LEÃO, 1926; MONCORVO FILHO, 1913), acabou por reforçar a necessidade de se fazer algo que tomasse por base o trabalho da escola, considerando que a estrutura de atendimento de saúde da infância na cidade do Rio de Janeiro não conseguia dar resposta ao problema (SILVA, 2017). É sintomático observar que, na cerimônia de inauguração da primeira clínica escolar da cidade, com seus laboratórios e salas de tratamento, nos idos de 1930, seu mentor pronunciasse um discurso em que pedia a criação de mais essa instituição de saúde: a escola hospital.

É essa a grande lição dos sanatórios. Pois bem, senhores, organização idêntica tem sido dada aos serviços de higiene escolar. A extensão a todas as escolas do regime das classes silvestres, a educação sanitária das famílias dos alunos pelas enfermeiras, a educação física, a abertura de parques de recreio, a redução do número de horas de trabalho escolar, a obsessão pela vida ao ar livre, a assistência alimentar aos escolares, o exame médico periódico e o tratamento eficiente dos alunos em clínicas bem instaladas [...] são a garantia de um futuro mais risonho para a atual geração das crianças que frequentam as escolas públicas (CLARK, 1930a, p. 4-5). 
No conjunto das práticas instituídas na escola hospital, para cada ciclo de três horas de atividades, estabeleciam-se objetivos em termos médicos, terapêuticos, sociais, expressos na aquisição de rudimentos de civilização e modernidade. Tudo em nome da cura ou da utilidade de tais práticas para "diversas curas", com seus ciclos e repetições, no âmbito de uma instituição que buscava estabelecer uma pedagogia com seus objetivos e formas concretas para alcançar determinados resultados.

\section{Considerações finais}

"Meninos de Araruama", esse é o termo utilizado no final do discurso de inauguração da escola hospital e esse será o termo que utilizaremos para finalizar este artigo. Pouco sabemos sobre esses meninos e menos ainda sobre o que parecem ser duas meninas, assim consideradas por trajarem, em algumas fotos, uma espécie de vestido, semelhante a um traje de dormir em voga na época. Sobre elas, nenhuma linha foi descoberta nesta pesquisa, até mesmo sua identificação de gênero foi negada, não havendo nenhuma menção às suas doenças. Misturadas ao caráter masculino daquela experiência institucional, foram ainda mais duramente silenciadas.

Ainda que uma vez ou outra se tenha identificado algum nome, não temos muitas referências sobre as crianças que passaram pela escola hospital e foram expostas ao contato com a natureza e às atividades agrícolas encenadas nas fotografias examinadas, cujos sentidos procuramos indagar por meio de uma análise em que se buscou compreender os objetivos dessa instituição, o público a que se destinava, algumas das práticas adotadas e o lugar dessas práticas no projeto de formação pretendido. As imagens registradas de suas vidas para fora dos muros da instituição são precárias e incompletas - a única coisa que traziam de fora, segundo aqueles que registravam suas trajetórias, eram as doenças, o que oferece pistas de que eram, em sua maioria, crianças das zonas urbanas, misturadas a um pequeno grupo de crianças que moravam no campo. Em comum, apenas considerações muito negativas sobre seus lugares de pertencimento e suas histórias, silenciadas ao transporem as portas da instituição. 
FIGURA 3 - ESCOLA HOSPITAL JOSÉ DE MENDONÇA, EM ARARUAMA, ESTADO DO RIO DE JANEIRO

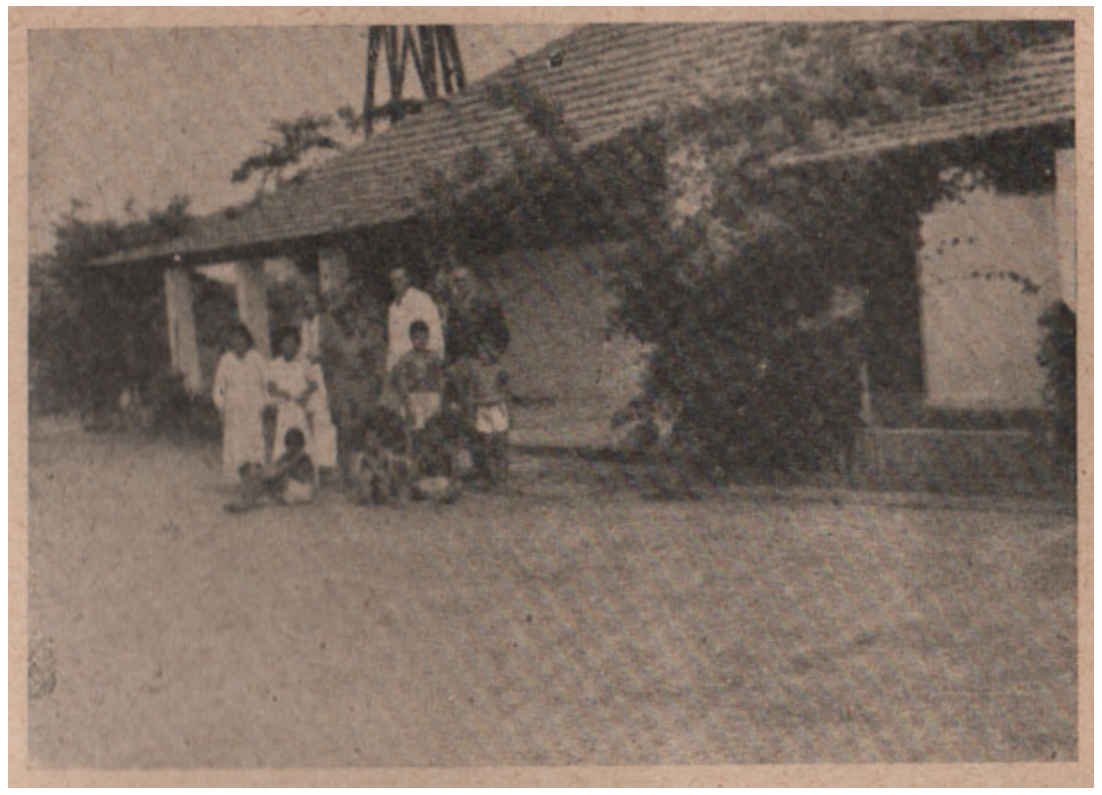

Nota: Grupo de alunos da instituição. Nota-se a presença de duas meninas à esquerda. Local: Araruama, Fazenda da Penha.

FONTE: (CLARK, 1943).

Capturadas em descrições que insistem na afirmação da precariedade de seu estado de saúde e de suas condições de vida, além de darem notícia dos tratamentos médicos a que foram submetidas, nada sabemos sobre elas. Não temos indícios sobre as brincadeiras que lhes agradavam, as suas visões de mundo, ou mesmo como encaravam aquele lugar onde foram abrigadas sob a justificativa de que seriam "mais bem" tratadas e educadas. Mais uma vez estamos diante de algo que aflige e cobra dos trabalhos em história da educação e da infância uma atitude crítica e reflexiva, que possibilite evidenciar as violências simbólicas que permeiam essa e outras histórias. $\mathrm{O}$ fato é que as histórias das crianças são escritas no mais das vezes por outros (quase sempre em suas relações com os adultos) e capturadas por campos do saber como a pedagogia, o direito, a assistência social e a medicina (ARIÈS, 1978). Restituir a esses sujeitos históricos carne e osso, sentimentos e visões de mundo é um anseio que nos mobiliza, assim como tem mobilizado gerações de estudiosos que têm se debruçado sobre o passado, indagando-se sobre as imagens sociais que os adultos (a sociedade) produzem das crianças. 


\section{REFERÊNCIAS}

ARIÈS, Philippe. História social da criança e da família. Rio de Janeiro: Zahar, 1978.

BAUBÉROT, Arnaud. Histoire du naturisme: Le mythe du retour à la nature. Rennes: PU Rennes, 2004.

BERTOLLI FILHO, Claudio. História social da tuberculose e do tuberculoso: 1900-1950. Rio de Janeiro: Editora FIOCRUZ, 2001.

CARVALHO, Marta Maria Chagas de. A escola e a República. São Paulo: Brasiliense, 1989.

CARVALHO, Marta Maria Chagas de. Molde nacional e fôrma cívica: higiene, moral e trabalho no projeto da Associação Brasileira de Educação (1924-1931). Bragança Paulista: Edusf, 1998.

CHALHOUB, Sidney. Cidade febril: cortiços e epidemias na Corte imperial. São Paulo: Companhia das Letras, 1996.

CLARK, Oscar Castelo Branco. Clínicas escolares. Boletim da Educação Pública, n. 2, Rio de Janeiro, p. 4-5, abr. 1930a.

CLARK, Oscar Castelo Branco. Higiene escolar. Folha Médica, Rio de Janeiro, p. 61-69, fev. 1930b.

CLARK, Oscar Castelo Branco. Escola Hospital José de Mendonça. Rio de Janeiro, 1939.

CLARK, Oscar Castelo Branco. O século da criança. Rio de Janeiro: Canton \& Reile, 1940.

CLARK, Oscar Castelo Branco. Jardins de infância e escolas hospitais. São Paulo: Livraria Acadêmica: Saraiva \& Cia, 1943.

CLARK, Oscar Castelo Branco. Política dos campos de saúde - escolas hospitais silvestres. Rio de Janeiro: Canton \& Reile, 1946.

CORBIN, Alain. O território do vazio: a praia e o imaginário ocidental. São Paulo: Companhia das Letras, 1989.

COUTO, Miguel. No Brasil só há um problema nacional: a educação do povo. Rio de Janeiro: Typ. do Jornal do Comércio, de Rodrigues \& C, 1927.

DALBEN, André. Mais do que energia, uma aventura do corpo: as colônias de férias escolares na América do Sul (1882-1950). 2014. 278 f. Tese (Doutorado em Educação) Universidade Estadual de Campinas, Campinas, 2014.

ESSUS, Ana Maria M. de S. Sob o signo da imagem: a produção fotográfica e o controle dos códigos de representação da classe dominante, no Rio de Janeiro, na primeira metade do século XX. 1990. 207 f. Dissertação (Mestrado em História) - Departamento de História, Universidade Federal Fluminense, Niterói, 1990. 
ESSUS, Ana Maria M. de S. Olho da História: Análise da imagem fotográfica na construção de uma memória sobre o conflito de Canudos. Acervo, Rio de Janeiro, v. 6, n. 1-2, jan./dez. 1993.

FOUCAULT, Michel. Vigiar e punir: nascimento da prisão. 34. ed. Petrópolis: Vozes, 2007.

GOFFMAN, Erving. Manicômios, prisões e conventos. São Paulo: Perspectiva, 1974.

HERSCHMANN, Micael M.; PEREIRA, Carlos A. Messeder (org.). A invenção do Brasil moderno: medicina, educação e engenharia nos anos 20-30. Rio de Janeiro: Rocco, 1994.

HOCHMAN, Gilberto. A era do saneamento: as bases da política de saúde pública no Brasil. São Paulo: HUCITEC, 2006.

KIRK, David. Physical culture, Physical education and relational analysis. Sport, Education and Society, London, v. 4, n. 1, p. 63-73, 1999. Disponível em: https://doi. org/10.1080/1357332990040105. Acesso em: 19 set. 2020

KOSSOY, Boris. Realidade e Ficções na trama fotográfica. São Paulo: Ateliê Editorial, 2000.

KOSSOY, Boris. Fotografia \& História. São Paulo: Ateliê Editorial, 2001.

LEÃO, Antônio Carneiro. O ensino na capital do Brasil. Rio de Janeiro: Tipografia do Jornal do Comércio, 1926.

LEITE, Miriam Moreira. Retratos de família: leitura da fotografia histórica. São Paulo: Editora da Universidade de São Paulo, 2000.

MONARCHA, Carlos. A reinvenção da cidade e da multidão - dimensões da modernidade brasileira: a Escola Nova. São Paulo: Cortez, Autores Associados, 1989.

MONCORVO FILHO, Arthur. Guia do médico escolar. Rio de Janeiro: Typ. Baptista de Souza, 1913.

MONTENEGRO, Nara Romero. Cultura física e suas manifestações no litoral de fortaleza (1925-1946): novos modos de se educar e de se divertir. 2020. Dissertação (Mestrado em Educação) - Universidade Estadual de Campinas, Campinas, 2020.

MORAES E SILVA, Marcelo; QUITZAU, Evelise Amgarten; SOARES, Carmen Lucia. Práticas educativas e de divertimento junto à natureza: a cultura física em Curitiba (1886-1914). Educação e Pesquisa, v. 44, p. 178-293, 2018. Disponível em: https:// dialnet.unirioja.es/servlet/articulo?codigo=7315175. Acesso em: 22 set. 2020

NAGLE, Jorge. Educação e sociedade na Primeira República. São Paulo: EPU; Rio de Janeiro: Fundação Nacional de Material Escolar, 1976.

NOFUENTES, Vanessa Carvalho. Um desafio do tamanho da nação: a campanha da Liga Brasileira Contra o Analfabetismo. 2008. 162 f. Dissertação (Mestrado em História Social) - Pontifícia Universidade Católica do Rio de Janeiro, Rio de Janeiro, 2008.

PAULILO, André Luiz. A Reforma Carneiro Leão no Distrito Federal (1922-1926). In: MIGUEL, Maria Elisabeth Blank; VIDAL, Diana Gonçalves; ARAUJO; José Carlos 
Souza. Reforma educacionais: as manifestações da Escola Nova no Brasil (1920-1946). Campinas: Autores Associados; Uberlândia: Edufu, 2011. p. 43-61.

PEREIRA. Antonio Martins. Da tuberculose na idade escolar. Rio de Janeiro: Clinica Escolar Oscar Clark, 1932.

OLIVEIRA, Marinice Sant'ana de. Em páginas impressas e nas ondas do rádio: ações educativas para combater a tuberculose. Curitiba, 1937-1952. 2012. 133f. Dissertação (Mestrado em educação) - Universidade Federal do Paraná, Curitiba, 2012.

ROCHA, Heloísa Helena Pimenta. Imagens do analfabetismo: a educação na perspectiva do olhar médico no Brasil dos anos 20. 1995. 147 f. Dissertação (Mestrado em Educação) Faculdade de Educação, Universidade Estadual de Campinas, Campinas, 1995.

SILVA, Henrique Mendonça da. A higiene escolar além das palavras: Oscar Clark e o tratamento médico escolar. 2017. 312f. Tese (Doutorado em Educação) - Universidade Estadual de Campinas, Campinas, 2017.

SOARES, Carmen Lucia. Três notas sobre natureza, educação do corpo e ordem urbana (1900-1940). In: SOARES, Carmen Lúcia (org.). Uma educação pela natureza: a vida ao ar livre, o corpo e a ordem urbana. Campinas: Autores Associados, 2016. p. 1-45.

VALENZUELA, Manuel Armijo; BACAICOA, Josefina San Martín. Curas balnearias y climáticas: talassoterapia y helioterapia. Espanha: Editorial Complutense, 1994.

VILLARET, Sylvain. Naturisme et éducation corporelle: des projets réformistes aux prises en compte politiques et éducatives (XIXe-milieu XXe siècles). Paris: L'Harmattan, 2005.

Texto recebido em 04/10/2020.

Texto aprovado em 23/03/2021. 